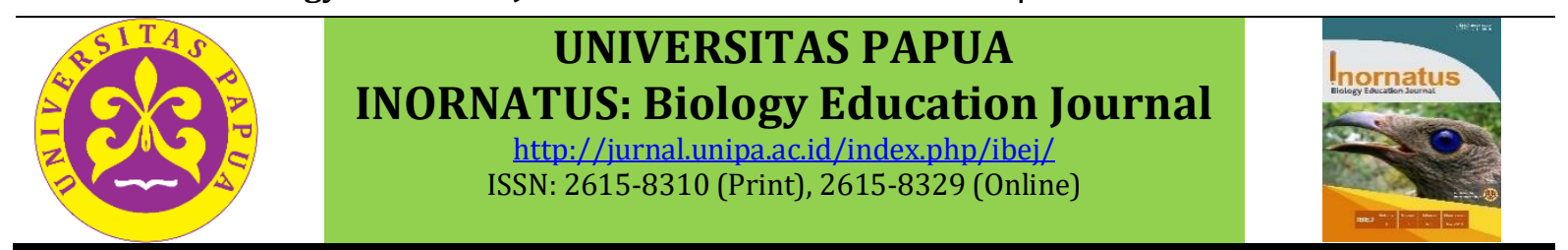

\title{
Problem-based learning in teaching excretory system materials: Does it affect student learning outcomes?
}

\section{Pembelajaran berbasis masalah dalam pengajaran materi sistem ekskresi: Apakah mempengaruhi hasil belajar siswa?}

\author{
Theresia Windywati Bongi Sogen*, Insar Damopolii, Johanis Paulus Kilmaskossu \\ 1Universitas Papua, Indonesia \\ *korespondensi penulis : theresia95sogen@gmail.com
}

\begin{abstract}
Problem-based learning (PBL) has been reported to be effective in improving student learning outcomes. Excretory system material is difficult material, and students experience problems in learning achievement. This research attempts to use PBM to enhance student learning outcomes about excretory system material. Quasi-experiment was used with a sample of 31 students (15 in the experimental class and 16 in the control class). Data on student learning outcomes were collected using tests. Non-parametric data analysis has been used to calculate learning outcomes data. The results of the research showed that there was no difference in learning outcomes between PBM and conventional classes ( $p>0.05$ ). This research concludes that student learning outcomes on excretory system material cannot be optimized by using PBM. It is necessary to optimize PBM implementation in biology classes, such as guidance to students and the use of problems in learning.
\end{abstract}

Keywords: Learning outcomes, conventional, optimization, PBM, excretory system

\begin{abstract}
Abstrak
Pembelajaran berbasis masalah (PBM) telah dilaporkan efektif meningkatkan hasil belajar siswa. Materi sistem ekskresi adalah materi sulit dan siswa mengalami masalah dalam pencapaian belajar. Riset ini berupaya menggunakan PBM untuk memperbaiki hasil belajar siswa tentang sistem ekskresi. Kuasi eksperimen digunakan dengan jumlah sampel sebanyak 31 siswa (15 di kelas eksperimen dan 16 di kelas kontrol). Data hasil belajar siswa dikumpulkan menggunakan tes. Analisis data non parametrik telah digunakan untuk menghitung data hasil belajar. Hasil riset menunjukkan bahwa tidak ada perbedaan hasil belajar antara kelas PBM da konvensional $(\mathrm{p}>0,05)$. Riset ini menyimpulkan bahwa hasil belajar siswa tentang sistem ekskresi belum dapat dioptimalkan dengan penggunaan PBM. Diperlukan optimalisasi terhadap pelaksanaan PBM dalam kelas biologi seperti bimbingan kepada siswa dan penggunaan masalah dalam pembelajaran.
\end{abstract}

Kata Kunci: Hasil belajar, konvensional, optimalisasi, PBM, sistem ekskresi

\section{Pendahuluan}

Model pembelajaran di kelas yang digunakan oleh guru menjadi faktor utama keberhasilan pembelajaran. Kemampuan pedagogik dan dukungan infrastruktur menjadi factor penentu keberhasilan (Frabun, Iwan, \& Wambrauw, 2018; Watem, Nunaki, \& Wambrauw, 2018). Strategi pengajaran dan pemanfaatan sumber belajar yang tepat mendukung keberhasilan pengajaran. Perbaikan pembelajaran harus tetap dilakukan mengingat pendidikan terus ada sepanjang hayat.

Peneliti mengobservasi sebuah sekolah SMP di Manokwari. Beberapa hal ditemukan selama observasi lapangan. Kurangnya kesempatan siswa untuk berekspresi selama pembelajaran yang berorientasi pada guru juga mengakibatkan siswa kurang 
tertarik untuk belajar biologi karena dianggap materi hafalan, dan siswa cenderung mengobrol dengan teman sebayanya saat pembelajaran berlangsung, mengakibatkan siswa menjadi kurang fokus. saat pembelajaran berlangsung. Namun, temuan pengamatan menunjukkan bahwa siswa terlibat aktif dalam pembelajaran mereka, tetapi beberapa siswa terlibat dalam permainan dengan teman-teman mereka di kelas, menyebabkan mereka kehilangan perhatian pada konten yang sedang dibahas.

Pelaksanaan pembelajaran yang kurang ideal akibat kondisi tersebut mengakibatkan hasil belajar siswa yang kurang. Selain itu, penerapan pembelajaran yang tidak efektif mengakibatkan sebagian besar siswa kurang giat belajar dan pencapaian hasil belajar yang tidak memenuhi syarat. Hal ini ditunjukkan dengan hasil belajar siswa yang terus berprestasi di bawah standar. Siswa yang tidak tuntas di kelas VIIIA berjumlah $35 \%$ dari 31 siswa, sedangkan siswa yang tuntas tidak tuntas di kelas VIIIB berjumlah 30\% dari 31 siswa. Kemampuan berpikir kritis siswa dalam pemecahan masalah juga kurang berkembang akibat pemilihan pendekatan pembelajaran yang tidak efektif.

Materi sistem ekskresi merupakan contoh materi sulit dalam pembelajaran bidang biologi. Nisak, (2013) melaporkan bahwa hasil observasinya menunjukkan bahwa lebih dari $40 \%$ siswa merespon bahwa materi ini sulit. Hasil laporannya juga menuliskan bahwa 50\% siswa tidak mencapai standar yang ditentukan. Amini, Nasution, Mulkan, dan Sugito (2018) melaporkan bahwa semakin tinggi aspek kognitif pada materi sistem ekskresi maka semakin sulit siswa memahaminya. Mereka melaporkan ada faktor internal dan eksternal yang mempengaruhi seperti sekolah, keluarga, psikologi, minat, materi, media, motivasi, Kesehatan, guru dan metode mengajar. Maka proses pengajaran perlu ditingkatkan.

Pembelajaran dapat ditingkatkan kualitasnya dengan penggunaan pembelajaran yang berbasis masalah (PBM). PBM bisa menjadi menarik jika dirancang dengan benar melalui proses pemecahan masalah dunia nyata (Stentoft, 2017). Guru yang menggunakan PBM berarti mereka membangun pedagogi sains yang penting dan meningkatkan profesionalisme sebagai guru (Cullen \& Jackson, 2018). PBM adalah sebuah metode pengajaran yang mengintegrasikan masalah dunia nyata untuk memberikan pengalaman berharga kepada siswa (Spronken-Smith \& Harland, 2009) karena mereka terlibat dalam kerja kolaboratif (Allen, Donham, \& Bernhardt, 2011). PBM menjadi metode efisien untuk pembelajaran dan siswa mendapatkan pemahaman mendalam tentang materi yang mereka pelajari (Jansson, Söderström, Andersson, \& Nording, 2015), metakognitif (Pratama, 2018) dan berpikir tingkat tinggi (Ramdiah, Abidinsyah, \& Mayasari, 2018). Siswa memperoleh keuntungan ganda ketika mereka terlibat dalam PBM dibanding tanpa PBM (Yadav, Subedi, Lundeberg, \& Bunting, 2011). Yadav et al. (2011) menyarankan penggunaan PBM untuk pengajaran materi dan guru yang sama dengan menggunakan kelas pembanding pada riset eksperimen berikutnya.

Fukuzawa, Boyd, dan Cahn, (2017) melaporkan bahwa siswa dalam kelas PBM harus mendapat dukungan baik dari pengajar agar mereka dapat mengoptimalkan pembelajaran mereka. Para peneliti ini mengungkap bahwa sebanyak 61\% siswa memberikan respon bahwa PBM mebantu mereka bejerka secara kolaboratif dalam grup. Sebanyak 80\% membutuhkan bimbingan pada saat pertama PBM dan menurun menjadi 54\% ketika penerapan tahap dua. Damopolii, Yohanita, Malatta, dan Yusuf, (2018) melaporkan bahwa penggunaan PBM dalam kelas biologi memberikan dampak positif terhadap perubahan hasil belajar siswa. Temuan peneliti adalah bahwa kognitif siswa pada PBM lebih baik, sedangkan di kelas tanpa PBM menunjukkan lebih dari $60 \%$ kognitif siswa berada kriteria kurang. Pertimbangan tidak hanya harus diberikan pada metode pengajaran dan pembelajaran saat menerapkan siswa pada PBM, tetapi juga harus 
dipertimbangkan bahwa siswa dapat memenuhi tujuan mereka selama mengikuti kelas PBM (Harun, Yusof, Jamaludin, \& Hassan, 2012). Riset ini berupaya menggunakan PBM pada pembelajaran sistem ekskresi untuk memperbaiki hasil belajar siswa .

\section{Metode}

Penelitian kuasi eksperimen ini dilaksanakan di salah satu SMP Negeri di Manokwari. Populasi penelitian sebanyak 121 siswa kelas VII SMP yang tersebar pada 4 kelas. Sampel yang digunakan dalam penelitian adalah dua kelas dengan jumlah 31 siswa. Total 15 siswa berada di kelas PBM (kelas perlakuan/eksperimen) dan kelas konvensional (Kontrol) sebanyak 16 siswa.

Perangkat dan instrumen untuk penelitian (rencana pembelajaran-RPP, lembar kerja siswa-LKPD, dan tes pengukur hasil belajar) disusun dan divalidasi oleh ahli dan praktisi. Tes berjumlah 10 berbentuk pilihan ganda dan 2 item berbentuk esai. Tes mengukur hasil belajar diberikan dua kali yaitu pre-tes (pre-HB) dan post-test (post-HB). Kriteria validasi dihadirkan pada Tabel 1.

Tabel 1. Interpretasi hasil validasi

\begin{tabular}{lc}
\hline Inverval & Keputusan \\
\hline $3,3 \leq$ skor $\leq 4$ & Sangat Valid dan dapat digunakan (tanpa revisi) \\
$2,6 \leq$ skor $\leq 3,2$ & Valid dan sedikit / minor revisi diperlukan \\
$1,8 \leq$ skor 2,5 & Kurang dan Valid besar / major revisi diperlukan \\
$1 \leq$ skor 1,7 & Tidak Valid dan tidak dapat digunakan \\
\hline
\end{tabular}

Data yang dikumpulkan selama penelitian dianalisis menggunakan non parametrik (Mann-Whitney) dikarena hasil uji Shapiro -Wilk tidak berdistribusi normal.

\section{Hasil dan Pembahasan}

Temuan riset yang dihadirkan dalam artikel ini terdiri dari hasil validasi, uji normalitas dan hasil uji t hasil belajar. Data dihadirkan dalam Tabel 2 - 5 .

Tabel 2. Hasil validasi perangkat dan instrumen

\begin{tabular}{lll}
\hline Perangkat/Instrumen & Skor & Kriteria \\
\hline Tes Hasil Belajar & 3,72 & Valid \\
RPP & 3,76 & Valid \\
LKPD & 3,90 & Valid \\
\hline
\end{tabular}

Tabel 2 menunjukkan bahwa perangkat dan instrument yang disusun telah memenuhi kriteria validasi oleh ahli dan praktisi. Perangkat dapat digunakan.

Tabel 3. Deskripsi pre-HB dan post-HB

\begin{tabular}{ccccc}
\hline \multirow{2}{*}{ Data } & \multicolumn{2}{c}{ Kontrol } & \multicolumn{2}{c}{ Eksperimen } \\
\cline { 2 - 5 } & Pre-HB & Post-HB & Pre-HB & Post-HB \\
\hline N & 16 & 16 & 15 & 15 \\
Mean & 22,34 & 39,69 & 25,33 & 52,33 \\
SD & 12,925 & 25,672 & 8,010 & 22,726 \\
Minimum & 5 & 10 & 15 & 20 \\
Maksimum & 40 & 90 & 50 & 90 \\
\hline
\end{tabular}


Tabel 3 mengungkap bahwa mean eksperimen dan kontrol berbeda. Mean pre-HB kedua kelas berbeda sebesar 2,99, sedangkan mean post-HB berbeda 12,64. Skor minimum dan maksimum pre-HB berbeda, kecuali skor maksimum untuk post-HB yang memiliki kesamaan yaitu 90. Selanjutnya pada Tabel $4-5$ menunjukkan hasil perbedaan signifikan.

Tabel 4. Hasil pengujian Shapiro-Wilk dan Mann-Whitney pre-HB

\begin{tabular}{|c|c|c|c|c|c|c|}
\hline \multirow[b]{2}{*}{ Kelas } & \multicolumn{3}{|c|}{ Shapiro-Wilk } & \multicolumn{3}{|c|}{ Mann-Whitney } \\
\hline & df & $P$ & Keputusan & $\mathbf{Z}$ & $P$ & Keputusan \\
\hline $\begin{array}{c}\text { Kontrol } \\
\text { Eksperimen }\end{array}$ & $\begin{array}{l}16 \\
15\end{array}$ & $\begin{array}{l}0,105 \\
0,001\end{array}$ & $\begin{array}{c}\text { Normal } \\
\text { Tidak Normal }\end{array}$ & $-0,641$ & 0,521 & Tidak \\
\hline
\end{tabular}

Hasil uji normalitas meningdikasikan bahwa data pre-HB kontrol normal dan eksperimen tidak, sehingga pengujian menggunakan Mann-Whitney. Hasil uji menunjukkan bahwa pre-HB kedua kelas tidak berbeda signifikan.

Tabel 5. Hasil pengujian Shapiro-Wilk dan Mann-Whitney post-HB

\begin{tabular}{|c|c|c|c|c|c|c|}
\hline \multirow{2}{*}{ Kelas } & \multicolumn{3}{|c|}{ Shapiro-Wilk } & \multicolumn{3}{|c|}{ Mann-Whitney } \\
\hline & df & $P$ & Keputusan & $\mathbf{Z}$ & $P$ & Keputusan \\
\hline $\begin{array}{c}\text { Kontrol } \\
\text { Eksperimen }\end{array}$ & $\begin{array}{l}16 \\
15\end{array}$ & $\begin{array}{l}0,035 \\
0,539\end{array}$ & $\begin{array}{c}\text { Tidak Normal } \\
\text { Normal }\end{array}$ & $-1,116$ & 0,264 & Tidak berbeda \\
\hline
\end{tabular}

Hasil uji normalitas meningdikasikan bahwa data post-HB eksperimen normal dan kontrol tidak, sehingga pengujian menggunakan Mann-Whitney. Hasil uji menunjukkan bahwa post-HB kedua kelas tidak berbeda signifikan.

Berdasarkan temuan riset ini mengungkap bahwa walaupun mean kedua kelas berbebeda, tetapi hasil belajar di PBM tidak menunjukkan perbedaan signifikan dengan konvensional diakhir pembelajaran. Beberapa hasil riset sebelumnya menunjukkan bahwa hasil belajar di PBM berbeda dengan non PBM. Misalnya riset Kurniahtunnisa, Dewi, dan Utami (2016) dan riset Novitasari, Anggraito, dan Ngabekti (2015). Hasil temuan peneliti menunjukkan temuan yang berbeda dengan riset sebelumnya.

Pada riset yang peneliti lakukan menemukan fakta bahwa sebagian siswa kurang memiliki minat untuk menyelesaikan masalah yang terdapat pada LKPD. Ketika siswa dihadapkan permasalahan yang ada di LKPD siswa tidak memiliki kemauan untuk mencoba mengerjakan LKPD. Terlihat pada pertemuan pertama, dimana beberapa siswa bergantung pada siswa lainnya karena dianggap masalah dikerjakan sulit untuk diselesaikan. Umpan balik pun dibutuhkan untuk meningkatkam kualitas diskusi dalam PBM (Dolmans \& Gijbels, 2013). PBM tidak efektif karena kekurangan bimbingan (Baran \& Sozbilir, 2018) sehingga performa kognitif siswa menurun (Sweller, Kirschner, \& Clark, 2007). Peneliti menduka adanya kurang maksimalnya bimbingan saat siswa mengerjakan LKPD saat pembelajaran.

Tingkat keragaman siswa juga mempengaruhi proses pembelajaran, hal ini dilihat dari kemampuan siswa yang beragam. Pada awal diskusi terlihat siswa yang tergolong mampu lebih mendominasi diskusi, sedangkan siswa yang kurang mampu terlihat bergantung pada ketua kelompok. Jika dalam PBM siswa tidak seius dalam pembelajaran maka hasil yang mereka capai tidak akan maksimal (Narmaditya, Winarning, \& Wulandari, 2017). Selain itu, faktor manusia adalah satu set variabel pengganggu yang 
dapat mempengaruhi proses belajar siswa dan akibatnya mempengaruhi pelaksanaan PBM dan hasil penelitian (Hung, 2011).

Beberapa hal yang tidak bisa dikontrol oleh peneliti mungkin sebagai penyebab rendahnya hasil belajar siswa. Walaupun mean hasil belajar siswa kelas PBM lebih tinggi, namun tidak menunjukkan perbedaan yang signifikan. Hal lain diduga juga mempengaruhi implementasi PBM. Siswa kurang merespon atau kurang setuju (22\%) dalam hal menginginkan lebih banyak penggunaan PBM dama pembelajaran, sementara itu sebanyak 41\% meminta untuk mengurangi penggunaan PBM (Fukuzawa et al., 2017). Riset ke depannya perlu dilakukan untuk meneliti secara kualitatif mengapa hasil belajar pada kelas PBM tidak maksimal. Peneliti lain juga dapat menggunakan bantuan media lain untuk mengoptimalkan PBM. Seperti yang media audio-visual yang digunakan oleh Novitasari et al. (2015).

\section{Simpulan}

Riset ini telah memperoleh fakta bahwa hasil belajar siswa tentang sistem ekskresi di kelas PBM tidak menunjukkan perbedaan signifikan dengan hasil belajar pada kelas non PBM (konvensional). Riset ini menyimpulkan bahwa hasil belajar siswa tentang sistem ekskresi tidak dapat dioptimalkan dengan penggunaan PBM. Diperlukan optimalisasi terhadap pelaksanaan PBM dalam kelas biologi seperti bimbingan kepada siswa dan penggunaan masalah dalam pembelajaran.

\section{Referensi}

Allen, D. E., Donham, R. S., \& Bernhardt, S. A. (2011). Problem-based learning. New Directions for Teaching and Learning, 2011(128), 21-29. https://doi.org/10.1002/tl.465

Amini, F., Nasution, M. Y., Mulkan, M., \& Sugito, H. (2018). Analisis kemampuan kognitif dan kesulitan belajar siswa materi sistem ekskresi di SMA Negeri 1 Karang Baru. Jurnal Pelita Pendidikan, 6(4), 225-232. https://doi.org/10.24114/jpp.v6i4.11053

Baran, M., \& Sozbilir, M. (2018). An Application of Context- and Problem-Based Learning (C-PBL) into Teaching Thermodynamics. Research in Science Education, 48(4), 663689. https://doi.org/10.1007/s11165-016-9583-1

Cullen, T., \& Jackson, C. D. (2018). Problem-Based Learning in the Life Science Classroom, K-12. Interdisciplinary Journal of Problem-Based Learning, 12(1). https://doi.org/10.7771/1541-5015.1771

Damopolii, I., Yohanita, A. M., Malatta, F. H., \& Yusuf, F. M. (2018). Pengaruh Model Pembelajaran Berbasis Masalah terhadap Hasil Belajar Kognitif Siswa Kelas VII SMP. Edubiotik: Jurnal Pendidikan, Biologi Dan Terapan, 3(01), 43-52. https://doi.org/10.33503/ebio.v3i01.78

Dolmans, D., \& Gijbels, D. (2013). Research on problem-based learning: future challenges. Medical Education, 47(2), 214-218. https://doi.org/10.1111/medu.12105

Frabun, R. F., Iwan, I., \& Wambrauw, H. L. (2018). The effectiveness of laboratory use in supporting biology practicums in high schools throughout Manokwari Regency. Inornatus: Biology Education Journal, 1(1), 1-9. https://doi.org/10.30862/inornatus.v1i1.109

Fukuzawa, S., Boyd, C., \& Cahn, J. (2017). Student Motivation in Response to Problembased Learning. Collected Essays on Learning and Teaching, 10, 175-188. https://doi.org/10.22329/celt.v10i0.4748

Harun, N. F., Yusof, K. M., Jamaludin, M. Z., \& Hassan, S. A. H. S. (2012). Motivation in Problem-based Learning Implementation. Procedia - Social and Behavioral Sciences, 
56, 233-242. https://doi.org/10.1016/j.sbspro.2012.09.650

Hung, W. (2011). Theory to reality: a few issues in implementing problem-based learning. Educational Technology Research and Development, 59(4), 529-552. https://doi.org/10.1007/s11423-011-9198-1

Jansson, S., Söderström, H., Andersson, P. L., \& Nording, M. L. (2015). Implementation of Problem-Based Learning in Environmental Chemistry. Journal of Chemical Education, 92(12), 2080-2086. https://doi.org/10.1021/ed500970y

Kurniahtunnisa, K., Dewi, N. K., \& Utami, N. R. (2016). Pengaruh model problem based learning terhadap kemampuan berpikir kritis siswa materi sistem ekskresi. Journal of Biology Education, 5(3), 310-318. https://doi.org/10.15294/jbe.v5i3.14865

Narmaditya, B., Winarning, W., \& Wulandari, D. (2017). Impact of Problem-Based Learning on Student Achievement in Economics Course. Classroom Action Research Journal, 1(1), 1-11. https://doi.org/10.17977/um013v1i12017p001

Nisak, K. (2013). Pengembangan perangkat pembelajaran ipa terpadu tipe connected pada materi pokok sistem ekskresi untuk kelas IX SMP. PENSA: E-Jurnal Pendidikan Sains, 1(1). Retrieved from https://ejournal.unesa.ac.id/index.php/pensa/article/view/1371

Novitasari, R., Anggraito, Y. U., \& Ngabekti, S. (2015). Efektivitas model problem based learning berbantuan media audio-visual terhadap motivasi dan hasil belajar siswa pada materi sistem ekskresi. Journal of Biology Education, 4(3), 298-303. https://doi.org/10.15294/jbe.v4i3.9583

Pratama, A. T. (2018). Improving metacognitive skills using problem based learning (PBL) at natural science of primary school in deli serdang, indonesia. Biosfer, 11(2), 101-107. https://doi.org/10.21009/biosferjpb.v11n2.101-107

Ramdiah, S., Abidinsyah, H., \& Mayasari, R. (2018). Problem-based learning: Generates higher-order thinking skills of tenth graders in ecosystem concept. Jurnal Pendidikan Biologi Indonesia, 4(1), 29-34. https://doi.org/10.22219/jpbi.v4i1.5490

Spronken-Smith, R., \& Harland, T. (2009). Learning to teach with problem-based learning. Active Learning in Higher Education, 10(2), 138-153. https://doi.org/10.1177/1469787409104787

Stentoft, D. (2017). From saying to doing interdisciplinary learning: Is problem-based learning the answer? Active Learning in Higher Education, 18(1), 51-61. https://doi.org/10.1177/1469787417693510

Sweller, J., Kirschner, P. A., \& Clark, R. E. (2007). Why Minimally Guided Teaching Techniques Do Not Work: A Reply to Commentaries. Educational Psychologist, 42(2), 115-121. https://doi.org/10.1080/00461520701263426

Watem, M., Nunaki, J. H., \& Wambrauw, H. L. (2018). Profile of Infrastructure and Pedagogic Competencies of Teachers in SMP and SMA/SMK in Waisai District, Raja Ampat Regency, West Papua Province. Inornatus: Biology Education Journal, 1(1), 10-29. https://doi.org/10.30862/inornatus.v1i1.16

Yadav, A., Subedi, D., Lundeberg, M. A., \& Bunting, C. F. (2011). Problem-based Learning: Influence on Students' Learning in an Electrical Engineering Course. Journal of Engineering Education, 100(2), 253-280. https://doi.org/10.1002/j.21689830.2011.tb00013.x 